\title{
Family communication about positive BRCA1 and BRCA2 genetic test results
}

Bobbi McGivern, MS $S^{1}$, Jessica Everett, $M S^{2,3}$, Geoffrey G. Yager, PhD ${ }^{4}$, Robert C. Baumiller PhD ${ }^{5}$, Amanda Hafertepen, $B S^{3}$, and Howard M. Saal, $M D^{2,3}$

\begin{abstract}
Purpose: The identification of a BRCA1 or BRCA2 genetic mutation can provide important health information to individuals who receive this result, but it can also provide crucial cancer risk information to family members. Most of the research on communication of genetic test results has focused on first degree relatives. The purpose of this retrospective study was to examine the process of communicating a positive BRCA1 or BRCA2 genetic test result to male and female first, second, and third degree relatives. Methods: Participants were 38 female mutation carriers who responded to a written survey assessing the number and relationship of relatives informed, methods used to inform relatives, topics discussed, and motivations and barriers for communication. Results: Overall, 59\% (470/803) of first, second, and third degree relatives were informed. The proportion of informed parents, siblings, and offspring was nearly twice that of more distant relatives including nieces, nephews, aunts, uncles, grandchildren, and cousins ( $88 \%$ versus $45 \% ; P=0.02$ ). The method of communication differed by the gender of the relative, as did some of the topics discussed. The most important reasons for discussing the genetic test results were (1) to inform the relatives of their risk, (2) to suggest that they be tested, and (3) to fulfill a perceived duty to inform. The major barrier to communication was little contact and/or emotionally distant relationships.

Conclusion: Female mutation carriers act on a perceived duty to inform close relatives of their positive test result; however, there is a need for genetic counseling strategies that address communication with more distant relatives.
\end{abstract}

Genet Med 2004:6(6):503-509.

Key Words: family communication, BRCA1 and BRCA2, genetic testing, genetic counseling.

Genetic information is rapidly becoming an integral part of clinical management for numerous medical conditions. The current medical model limits the delivery of genetic information to the individual seeking services, when in reality the information has implications for the entire family. Because of confidentiality, privacy issues, and health care regulations, the responsibility for sharing genetic test results with relatives falls on the index patient who may not be prepared or willing to assume this role. Understanding the determinants of communication about genetic test results will assist health care providers in addressing this critical issue.

Previous research studies have explored family communication about a variety of genetic conditions; however, the bulk of research on family communication with regard to genetic test-

\footnotetext{
From the ${ }^{1}$ Clinical Cancer Genetics, MD Anderson Cancer Center, Houston, Texas; ${ }^{2}$ Human Genetics Division, Cincinnati Children's Hospital Medical Center, Cincinnati, Ohio; ${ }^{3} \mathrm{He}$ reditary Cancer Program, Cincinnati Children's Hospital Medical Center, Cincinnati, Ohio; ${ }^{4}$ College of Education, University of Cincinnati, Cincinnati, Ohio; and ${ }^{5}$ Department of Philosophy, Xavier University, Cincinnati, Ohio.

Bobbi McGivern, MS, Genetic Counselor, Clinical Cancer Genetics, M.D. Anderson Cancer Center, 1500 Holcombe Blvd., Box 209, Houston, Texas 77030.

Received: April 8, 2004.

Accepted: May 14, 2004.
}

DOI: 10.1097/01.GIM.0000144014.91237.A1 ing has focused on hereditary breast and ovarian cancer syndrome. ${ }^{1-9}$ This is likely due to the increased availability and utilization of cancer genetic counseling services as well as the complex clinical and psychological issues related to testing for cancer risk. ${ }^{10-12}$ Two major breast cancer genes, BRCA1 and $B R C A 2$, are responsible for $5 \%$ to $10 \%$ of breast and ovarian cancer cases. Mutations in these genes are inherited in an autosomal dominant manner and confer an inherited predisposition to breast, ovarian, and other cancers. ${ }^{13-15}$

DNA-based testing for BRCA1 and BRCA2 cancer-predisposing mutations is available on a clinical basis. The identification of a disease-associated mutation in an individual allows for predictive testing of other at-risk family members. A primary goal of risk assessment for hereditary cancer is to enhance screening and to increase awareness of options for risk reduction. Choices available to individuals with an identified $B R C A 1$ or BRCA2 mutation include surveillance, prophylactic surgery, and chemoprevention. ${ }^{16,17}$

Most prior research has focused on communication of $B R C A 1$ and BRCA2 test results with siblings and children. These studies found that the majority of male and female participants informed siblings and children of their test results, whether these results were positive, negative, or inconclusive. ${ }^{2,7,18} \mathrm{~A}$ recent study gave a more comprehensive view of family communication by also examining the process and con- 
tent of the communication process. ${ }^{5}$ This study focused on communication with sisters and found that mutation carriers communicated their results to significantly more sisters as compared to noncarriers. ${ }^{5}$ Communication motivations for carriers included the desire for emotional support and advice about medical decisions. Mutation carriers were also more likely to discuss discrimination and recommendations for cancer management.

A major limitation of prior studies was that the participants were often from cancer family registries where communication about cancer in general could be increased, and multiple family members could be receiving genetic test results at the same time. Another limitation was the relatively small number of mutation carriers included in the more recent studies on family communication $\left(n=16,{ }^{5} n=24,{ }^{1}\right.$ and $\left.n=34^{2}\right)$.

More recently, Claes et al. ${ }^{1}$ evaluated communication between subjects who were tested for BRCA1 and BRCA2 mutations and more distant relatives including aunts, uncles, and cousins in addition to children, parents, and siblings. Again, the majority of individuals informed some or all of their children and siblings of the test result whether it was conclusive or inconclusive. Communication with distant relatives was more problematic with the major reason for not informing distant relatives being little or superficial contact with the family member. This study expanded the information on family communication about BRCA1 and BRCA2 genetic test results; however, these results need to be validated.

The aim of the current study was to provide additional information about family communication of $B R C A 1$ and $B R C A 2$ genetic test results. It is the second study to assess communication patterns beyond first degree relatives and is the first to examine communication with nieces, nephews, and grandchildren. It is limited to women with a deleterious BRCA1 or $B R C A 2$ mutation, which may be more relevant to family members than negative or inconclusive results. This is because the identification of a disease-causing mutation allows for predictive testing in family members and defines their risk more clearly than an inconclusive result does. This study describes the motivations, barriers, method, and content of communication. Much of the data are presented based on gender of the relative in order to highlight some of the gender differences that were seen in our examination of communication. The current study is important because inadequate communication can lead to inaccurate risk perception for uninformed family members.

\section{MATERIALS AND METHODS}

\section{Study design and sample}

A retrospective cohort study design involving women who had previously tested positive for a $B R C A 1$ or $B R C A 2$ gene mutation was used to examine each subject's communication with her family regarding the test result. Mutation carriers were identified from the Cincinnati Children's Hospital Medical Center Hereditary Cancer Program (HCP) patient data- base, which contains information from individuals seen since the establishment of the program in 1996.

Eligible female participants had all obtained genetic testing for BRCA1 and BRCA2 through the HCP and had been found to carry a deleterious mutation associated with an increased risk for developing cancer. Eligible participants were the first members of their families to undergo genetic testing for $B R C A 1$ and BRCA2.

\section{Data collection}

The institutional review boards of Cincinnati Children's Hospital Medical Center and the University of Cincinnati approved this study before implementation. Eligible subjects were contacted and invited to participate via mail. They received a cover letter explaining the aim of the study and the study's voluntary nature, a consent to participate in the study, and a four-page survey designed by the authors to evaluate family communication about the subject's genetic test result. Subjects were asked to review the consent form and maintain it for their own records. The consent form and questionnaire were each given a unique study number that was used to prevent duplicate analysis of questionnaires.

All eligible subjects received a mailing in December 2002. A second mailing was sent to all subjects in January 2003. For each survey that was completed and returned, a $\$ 5$ donation to a regional cancer-related organization was made.

\section{Measures}

The self-reported questionnaire consisted of 7 sections with a total of 27 close-ended questions and 2 open-ended questions. The close-ended questions assessed the proportion, identity, and gender of relatives who were personally informed of the positive genetic test result, the motivations and barriers for communication to family members, and the method and content of the communication process. Examples of how the questions were presented are as follows: "When you first informed relatives of your test result, which of the following methods did you use," "Which of the following topics did you discuss with the relatives that you informed," and "How important were each of the following in your decision to inform (or not to inform) your relatives."

Questions eliciting demographic information about the respondent, the number of relatives who had themselves undergone genetic testing, and which relatives were indirectly informed of the test results were also included. Open-ended questions were to allow participants to provide information in their own words, and responses were not used for specific analyses.

Some questions from this survey were adapted from a telephone interview designed and utilized previously. ${ }^{5}$ Before use, the survey was pilot tested by a female BRCA1 mutation carrier.

\section{Data analysis}

All data were initially entered into a spreadsheet created on Microsoft Excel (2000). Demographic data regarding nonre- 
spondents were obtained from the Hereditary Cancer Program database (Microsoft Access 1997) and entered into the investigator database after removal of identifying information. Median household income data were estimated based on zip code and obtained from the United States Census Bureau. ${ }^{19}$

Data analysis was performed using the SPSS System for Windows, release 11.0.1. Relationships between categorical variables (nominal and ordinal) were examined by Chi Square analysis. Fisher exact test was used for this analysis when a $2 \times$ 2 table contained cells with expected counts $<5$. Independent samples $t$ test analysis was used for continuous, numeric variables. The general linear model of repeated measures was used to compare the proportion of first, second, and third degree relatives informed by each subject. The nonparametric signed ranks test was used to evaluate Likert scale questions. In all cases, $P$-values of 0.05 or lower were considered statistically significant.

\section{RESULTS}

\section{Response rate and characteristics}

A total of 78 women received a positive result for a diseaseassociated mutation in BRCA1 and/or BRCA2 through the HCP. Thirteen were excluded because they were tested after a mutation in the family had previously been identified. One woman was excluded because she assisted with the development of the study questionnaire. Of the remaining 64 women, one was deceased and one could not be located. Thus, the study questionnaire was mailed to 62 eligible subjects.

Of the 62 study questionnaires that were mailed, 39 were completed and returned (62.9\%). The majority were returned in the first mailing $(n=31)$. Because the second mailing was to all 62 subjects instead of only to nonrespondents, it was possible for subjects to return the survey in both mailings. Using the survey identification number, we found that one individual did return two questionnaires, and her second questionnaire was excluded from all analyses. Respondents $(n=38)$ and nonrespondents $(n=24)$ did not differ significantly by race, religion, education, age, time since testing, whether the woman had cancer, or median household income as determined by zip code.

Although our intent was to identify study participants who were the first in the family to be tested, this was not true for all respondents. Two sisters who each responded were seen together for initial counseling and genetic testing and were together, the first family members to be tested. They received their positive test results simultaneously and were both included in the analysis. Two respondents indicated that they were not the first family members to be tested. Analyses were done with and without these two subjects and no significant differences were found; therefore, reported data include their surveys.

Characteristics of respondents are summarized in Table 1. The mean age of the respondents was 48.1 years, median was 47 years, and ages ranged from 23 to 77 years. An average of 2.4
Table 1

Characteristics of respondents $(n=38)$

\begin{tabular}{|c|c|c|c|}
\hline Characteristic & Category & $\%$ & $n$ \\
\hline \multirow[t]{2}{*}{ Race } & Caucasian & 97 & 37 \\
\hline & Native American & 3 & 1 \\
\hline \multirow[t]{3}{*}{ Marital status } & Married & 92 & 35 \\
\hline & Divorced or separated & 5 & 2 \\
\hline & Single & 3 & 1 \\
\hline \multirow[t]{6}{*}{ Highest education level } & Elementary school & 3 & 1 \\
\hline & High school & 11 & 4 \\
\hline & Some college & 24 & 9 \\
\hline & College degree & 37 & 14 \\
\hline & Graduate or beyond & 18 & 7 \\
\hline & No response & 8 & 3 \\
\hline \multirow[t]{4}{*}{ Annual household income } & $\leq \$ 25,000$ & 8 & 3 \\
\hline & $>\$ 25,000$ but $<\$ 75,000$ & 29 & 11 \\
\hline & $\geq \$ 75,000$ & 61 & 23 \\
\hline & No response & 3 & 1 \\
\hline \multirow[t]{5}{*}{ Religion } & Catholic & 47 & 18 \\
\hline & Jewish & 18 & 7 \\
\hline & Protestant & 29 & 11 \\
\hline & Other & 3 & 1 \\
\hline & No response & 3 & 1 \\
\hline \multirow[t]{2}{*}{ Affected with cancer } & Yes & 79 & 30 \\
\hline & No & 21 & 8 \\
\hline \multirow[t]{3}{*}{ Genetic mutation } & $B R C A 1$ & 76 & 29 \\
\hline & $B R C A 2$ & 18 & 7 \\
\hline & Both $B R C A 1$ and $B R C A 2$ & 5 & 2 \\
\hline
\end{tabular}

years had passed since receiving the test result with time intervals ranging from 5 to 72 months.

\section{Relatives informed or not informed}

Thirty-seven of the 38 respondents personally informed at least one at-risk relative of the test result. The one respondent who did not inform any family members was adopted and was not able to locate any biological relatives.

The 37 subjects who shared results with at least one family member reported having 803 living relatives including parents, children, siblings, nieces, nephews, and grandchildren, as well as aunts, uncles, and cousins from the affected side of the family. Overall, 470 of the 803 relatives (59\%) were personally informed of the test result.

Sisters were most likely to be informed with $100 \%$ of sisters being told $(n=63)$ (see Fig. 1). Respondents reported informing 68 of 73 brothers (93\%). The 5 brothers not informed were from 3 different families. Respondents reported having 15 


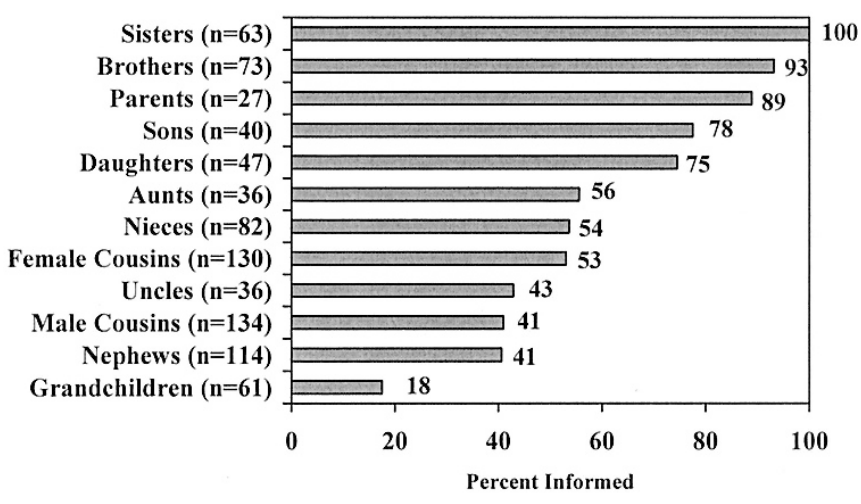

Fig. 1. Percent of relatives informed of the BRCA1 or $B R C A 2$ test result.

mothers and 12 fathers who were living. On average, each respondent reported having 21 at-risk relatives.

Respondents reported sons, daughters, nieces, nephews, and grandchildren of any age. Fifteen of the 31 sons informed of the test result $(48 \%)$ were $<18$ years old at the time of disclosure. Of the 35 daughters informed, 12 (34\%) were $<18$ years of age when informed.

Aunts, uncles, and cousins were reported for only the side of the family at risk for the mutation. Sixty-five percent of respondents reported that the mutation originated on the maternal side of the family $(n=24), 27 \%$ reported paternal side $(n=$ $10)$, and $8 \%$ were unsure $(n=3)$. If the subject was unsure, relatives from both sides of the family were reported.

First-degree relatives (children, siblings, and parents) were informed of the test result more often than second or third degree relatives (aunts, uncles, nieces, nephews, grandchildren, and cousins) ( $88 \%$ versus $45 \% ; P=0.02)$. The difference between informed males and females in each category was not significant (see Fig. 2).

Seventeen of the 37 respondents (46\%) informed $<50 \%$ of their relatives of the test result. Those that informed $<50 \%$ of relatives did not differ from those that informed $>50 \%$ of relatives by age, race, income, marital status, years since test-

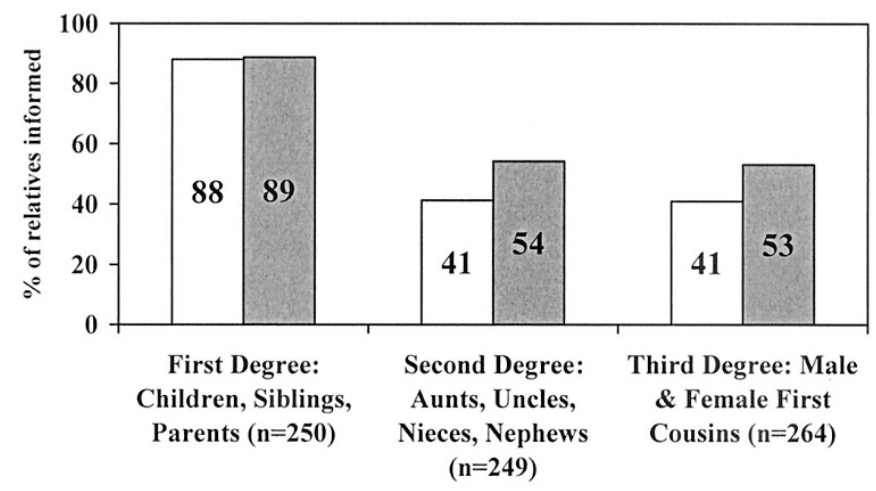

$\square$ Male Relatives $\square$ Female Relatives

Fig. 2. Percent of relatives informed based on gender and degree of relatedness. Grandchildren are excluded from the Figure, because the genders of the grandchildren were not elicited. ing, whether they were affected with cancer, or $B R C A$ mutation type.

\section{Method and content of communication}

Methods used most for communicating the test result to male and female relatives are summarized in Figure 3. Nine percent of respondents used another method to inform male relatives such as indirectly informing the male relative via another family member.

Respondents reported that many topics were discussed with relatives who were informed of the test result (see Table 2). The number of responses to these questions ranged from 10 to 34 because some respondents did not inform certain relatives of the result and therefore could not answer the question. Others left portions of the question blank for unknown reasons.

\section{Motivations and barriers for communication}

The most important reasons for discussing the test result with family members were (1) to inform them of their risk, (2) to fulfill a duty to inform, and (3) to suggest testing (see Fig. 4). Advice on treatment, emotional support, and suggesting testing were significantly less important when communicating test results to male relatives as compared to female relatives. The number of responses ranged from 28 to 37 for this question. Several respondents left portions of the question blank for unknown reasons.

The major barriers to communicating the test result were not being close to and not being in contact with relatives (see Fig. 5). There were no significant differences based on the genders of the relatives not informed. The number of responses ranged from 10 to 15 for this question because some respondents informed all relatives. Others left portions of the question blank for unknown reasons.

\section{Relatives indirectly informed}

Sixty-one percent of respondents said that they did not directly inform some relatives of the test result because they depended on another family member to do it. Of the 22 who

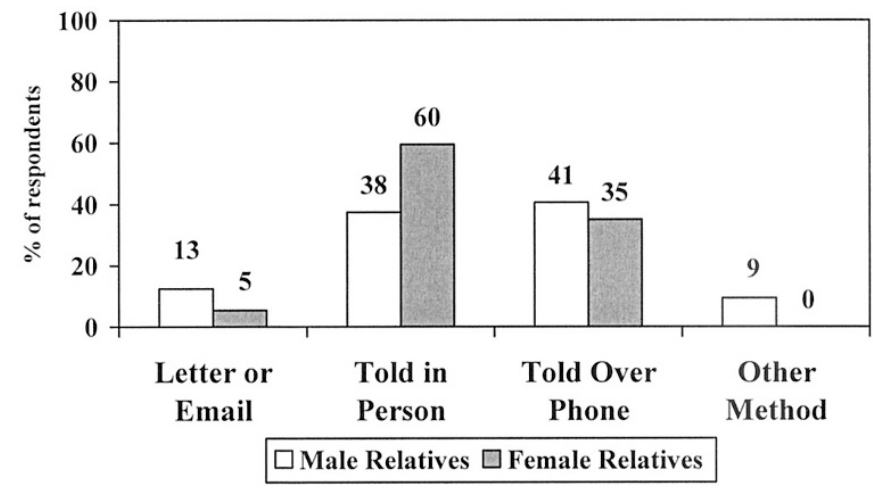

Fig. 3. Percent of respondents and the method they used most often to inform male and female relatives of the test result. Percentages were calculated with the number of participants who responded to the question as the denominator ( $n=37$ for female relatives; $n$ $=32$ for male relatives) 
Table 2

Topics discussed with family members

\begin{tabular}{|c|c|c|c|}
\hline Topic discussed & $\begin{array}{c}\text { Percent who } \\
\text { discussed topic } \\
\text { with male relatives } \\
\%(n / \text { total })\end{array}$ & $\begin{array}{c}\text { Percent who } \\
\text { discussed topic with } \\
\text { female relatives } \% \\
(n / \text { total })\end{array}$ & $P$ value \\
\hline Surgery guidelines & $40(10 / 25)$ & $78(25 / 32)$ & 0.003 \\
\hline Feelings about result & $62(16 / 26)$ & $89(31 / 35)$ & 0.011 \\
\hline Insurance discrimination & $68(20 / 29)$ & $89(31 / 35)$ & 0.022 \\
\hline Screening guidelines & $67(18 / 27)$ & $81(25 / 31)$ & 0.083 \\
\hline Cost of testing & $68(19 / 28)$ & $80(28 / 35)$ & 0.083 \\
\hline Family history of cancer & $90(26 / 29)$ & $97(34 / 35)$ & 0.161 \\
\hline Reasons why tested & $87(27 / 31)$ & $94(34 / 36)$ & 0.161 \\
\hline Risk of a mutation & $83(25 / 30)$ & $91(32 / 35)$ & 0.326 \\
\hline
\end{tabular}

Percentages were calculated with the number of participants who responded to each question as the denominator.

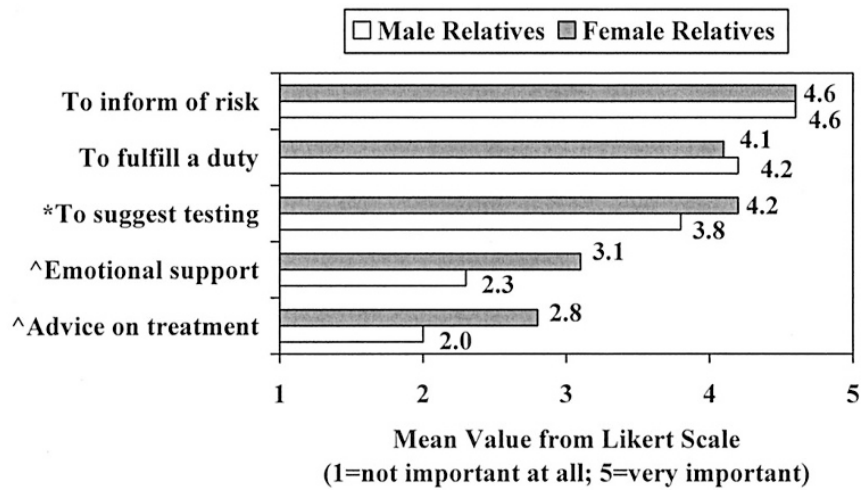

Fig. 4. Motivations for informing family members of the test result. ${ }^{*}$ Statistical significance at $P=0.05$. 'Statistical significance at $P=0.01$.

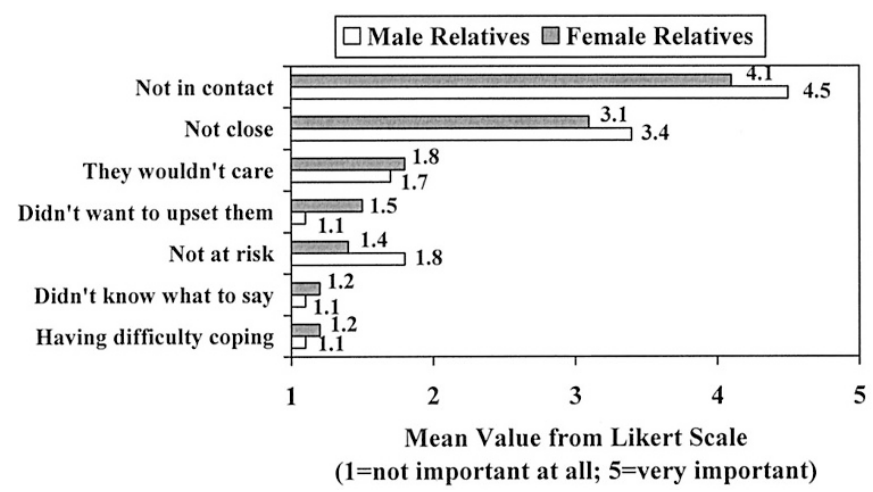

Fig. 5. Barriers to informing family members of the test result.

stated this, 8 specified that they let their siblings decide about informing nieces and nephews. Six respondents specified that they depended upon their mothers to inform brothers, aunts, and/or uncles of the test result. One woman said that her female cousins informed male cousins. Seven did not elaborate on their response.

\section{Number of relatives tested}

On average, respondents reported that 2.1 female relatives and 0.6 male relatives were tested for the familial BRCA mutation. Overall, $37 \%$ of the informed female relatives $(n=209)$ and $11 \%$ of the informed male relatives $(n=219)$ underwent genetic testing after learning of the result. Of note, some of the informed relatives were $<18$ years of age so testing would not have been offered to them.

\section{DISCUSSION}

This study examined the communication patterns of thirtyeight women who tested positive for a deleterious mutation in the BRCA1 and/or BRCA2 gene. The goal was to describe communication of the abnormal test result to male and female first, second, and third degree relatives. This included the method, content, motivations, and barriers of communication. As expected, participants communicated their test result to a large majority of first degree relatives (88\%), but significantly fewer second and third degree relatives were informed.

The proportion of informed first degree relatives in this study was higher than has been reported in other studies, and the difference in gender was not as large as other studies where females were significantly more likely to be informed. ${ }^{1-3,18}$ This may be because our population only included women with pathological BRCA1 or BRCA2 mutations, whereas other studies have included individuals with indeterminate or inconclusive results. It has been shown that individuals with abnormal test results are more likely to share their result than those who test negative or are found to have a variant of unknown clinical significance. ${ }^{1,2,5}$ This could certainly be a reflection of the differences in the counseling that is provided. For example, counselors may be more directive when discussing family communication with women who have a deleterious mutation and may therefore be more successful in emphasizing the importance of contacting at-risk relatives.

This study found that the major reason for informing relatives of the test result was to notify them of their risk. It was not surprising that more first degree relatives were informed of the test result because these relatives are at highest risk. Also, some women undergo testing in order to clarify cancer risk for other family members. ${ }^{20}$ This is especially true when a woman has already had cancer and has been treated surgically because the test result may not have a major impact her on medical management. Most participants in our study had already been diagnosed with cancer and may have felt a strong duty to inform relatives of this increased risk because this was a primary motive for being tested.

Study participants discussed some different topics with male versus female relatives and used different methods to inform them as well. It was not surprising that respondents discussed preventive surgery guidelines and insurance discrimination with fewer males than females, as these issues are likely less relevant to men. Male mutation carriers do not face the same surgical decisions as females. Also, participants reported that 
male relatives were less likely to be tested than female relatives ( $11 \%$ vs. $37 \%)$; therefore, male relatives may have had fewer questions about the insurance issues related to genetic testing.

Feelings about the test result were discussed with female relatives more often than male relatives. As suggested by other studies, communication with close, female family members may be a strategy used to cope with the abnormal test result.6,21 Also, most subjects informed female relatives of the test result in person, whereas male relatives were informed over the phone, in person, or by other means of communication such as indirect communication through another family member. Participants wanted more emotional support from female relatives; therefore, the difference in communication methods may indicate that they were most comfortable discussing their feelings face-to-face. The findings may also suggest a greater sense of importance or urgency when informing females of the mutation. To further address this issue, it would be useful to identify the amount of time that passed between receiving the test result and informing male versus female relatives.

Some participants found no difficulty with the communication process because the test result was not unexpected for them. This was illustrated by one respondent who stated, “. . .I was not shocked by the positive test result I received for $B R C A 1$, therefore, it was not difficult to inform my relatives; this testing was more for confirmation of what we suspected was a genetic mutation." Not wanting to upset the relative, not knowing what to say, and having difficulty coping were not identified as major communication barriers in this study. However, some participants did deal with these issues when informing certain relatives. One respondent stated, "The most difficult part was telling my brothers, since we had already lost my mother to breast cancer." Another wrote, "Since I was the first to take the test, I started feeling like I was responsible for the gene and was apologetic to my family. .."; These issues did not prevent participants from informing relatives but were cited by some as obstacles in the communication process.

The issue that did act as a barrier to communication was not being close or not being in contact with a relative. This is consistent with participants informing fewer second and third degree relatives as compared to first degree relatives as most individuals are closest to their parents, siblings, and children. This was illustrated by one respondent who stated, “. . .There is a big difference between telling your children and your extended family. I am very open with my children, they know what is going on and stay informed. I am not close with my extended family. They know their own cancer history." Previous studies support the finding that communication of a $B R C A 1$ or $B R C A 2$ test result can be hindered by a superficial relationship or lack of contact with a relative. ${ }^{1,4,5}$ This is a legitimate barrier, and it may be difficult for health care providers to develop strategies to help patients overcome it. Nonetheless, providers may be held responsible to at-risk relatives of the patients they see..$^{22}$ This obligation could be fulfilled by not only emphasizing to patients the importance of sharing the information, but also helping them to develop strategies that allow for effective communication while considering existing family dynamics.

Further research should focus on how health care providers can develop more successful strategies for promoting family communication. Different approaches will be required for different family members, and providers might be better able to assist patients if they understand the established communication patterns and relationships in the family. ${ }^{23}$ Communication about a genetic test result is selective rather than universal. Focusing on family during pretest counseling may help to predict potential problem areas. For example, if the patient has not informed family members about her personal cancer diagnosis, it is unlikely that she will inform them of a hereditary cancer syndrome. ${ }^{1}$ Once a problem area is recognized, the patient and professional can develop strategies such as providing literature for relatives or making plans to inform relatives indirectly via other family members as some of the participants in this study reportedly did.

Another important direction for future research is to evaluate the process of communication from the informed relative's perspective and to determine how that relative uses this information. In our study, participants reported that a minority of informed relatives had genetic testing, and some were frustrated when their relatives did not act on the information provided to them. For example, one respondent stated, “. . .Some [of my siblings] hesitated to get testing and that was hard for me; I wanted them to be proactive." It may be important to examine how the relative's perception of the information and of the communication process are related to his or her utilization of available genetic services.

Future research could also focus on determining the best way to inform and counsel children and young adults about increased cancer risk. In this study, $41 \%$ of children informed of the test result were $<18$ years of age at the time of disclosure. This is consistent with a recent report that the majority of early-onset breast cancer survivors felt their children should be provided with personal cancer risk information between the ages of 13 and 18 years. ${ }^{24}$ There is no known increased risk for childhood malignancy in individuals with a $B R C A 1$ or $B R C A 2$ mutation, nor is there an imminent medical benefit such as increased screening or behaviors to reduce cancer risk. It is not clear how the age of an informed child may influence psychological outcome or adherence to surveillance guidelines in adulthood. Thus, it is important to explore the positive and negative aspects of providing genetic risk information to children and young adults.

A final future direction is to expand research on communication about other hereditary cancer syndromes and to determine if information is conveyed differently based on the characteristics of the familial syndrome. Peterson et al. ${ }^{23}$ studied communication patterns in five families with hereditary nonpolyposis cancer (HNPCC) and found that participants felt it was "inappropriate" to directly share information about HNPCC with nieces, nephews, or cousins, unless it was first discussed with their parents present. Participants in the current study did inform nieces, nephews, and cousins of the test 
result. It would be interesting to know what other family members, if any, were included in the initial discussion. Also, this raises an important point that the nieces, nephews, and cousins who were not directly informed in this study may have received the information from other informed relatives.

Some limitations to this study exist. First, there was the potential for response bias in that nonrespondents may have informed fewer relatives. Second, the study was done retrospectively, which means there was potential for recall bias. Third, the small number of participants, although comparable to numbers cited in other studies, may have prevented us from detecting important predictors of family communication. Fourth, the content, motivations, and barriers of communication were reported by gender of the relative rather than for each relative individually. This generalization may have concealed differences that were based on the identity of the relative. For example, the desire to obtain emotional support may be higher when informing sisters versus female cousins, but this would not be reflected in our data. Lastly, the way in which we collected our data did not allow for us to analyze what percent of the uninformed relatives were under the age of 18 years. Age could have been an important factor in the decision to inform relatives.

In conclusion, the present study of family communication about positive $B R C A 1$ or $B R C A 2$ genetic test results provides an overview that is more extensive than other studies done on this topic. Female BRCA1 or BRCA2 mutation carriers informed most siblings, offspring, and parents of the test result; however, communication of the result to distant relatives including aunts, uncles, nieces, nephews, grandchildren, and cousins was less common. It is essential that family structure and established communication patterns be explored before testing so that strategies to overcome communication barriers are more successful after testing. Although many professionals and patients believe that confidentiality should be the highest priority, current case law is not completely consistent with respect to "duty to warn" issues. ${ }^{25,26}$ The ethical and legal dilemma of breaching patient confidentiality to warn relatives at high risk of inherited diseases can be avoided if professionals successfully help patients to overcome communication barriers.

\section{ACKNOWLEDGMENTS}

Financial support for this study was provided by an educational grant from the Bioethics Network of Ohio (BENO). We would like to thank Chanita Hughes, PhD, from the Department of Psychiatry at the University of Pennsylvania Medical Center for sharing her Family Communication Questionnaire with us. We acknowledge Judy Bean, $\mathrm{PhD}$, and Dawn Rothchild, RN, MSN, CNS, for valuable contributions to the study. Lastly, we are grateful to the women who participated in this study and so willingly shared their personal experiences.

\section{References}

1. Claes E, Evers-Kiebooms G, Boogaerts A, Decruyenaere M, Denayer L, Legius E. Communication with close and distant relatives in the context of genetic testing for hereditary breast and ovarian cancer in cancer patients. Am J Med Genet 2003;116A: 11-19.

2. Costalas JW, Itzen M, Malick J, Babb JS, Bove B, Godwin AK et al. Communication of $B R C A 1$ and $B R C A 2$ results to at-risk relatives: a cancer risk assessment program's experience. Am J Med Genet 2003;119C:11-18.

3. Daly MB, Barsevick A, Miller SM, Buckman R, Costalas J, Montgomery S et al. Communicating genetic test results to the family: a six-step, skills-building strategy. Fam Community Health 2001;24:13-26.

4. Green J, Richards M, Murton F, Statham H, Hallowell N. Family communication and genetic counseling: the case of hereditary breast and ovarian cancer. J Genet Couns 1997;6:45-61.

5. Hughes C, Lerman C, Schwartz M, Peshkin BN, Wenzel L, Narod S et al. All in the family: evaluation of the process and content of sisters' communication about BRCA1 and BRCA2 genetic test results. Am J Med Genet 2002;107:143-150.

6. Lerman C, Peshkin BN, Hughes C, Isaacs C. Family disclosure in genetic testing for cancer susceptibility: determinants and consequences. J Health Care Law Policy 1998;1:353-372.

7. Smith KR, Zick CD, Mayer RN, Botkin JR. Voluntary disclosure of BRCA1 mutation test results. Genet Test 2002;6(2):89-92.

8. Tercyak KP, Hughes C, Main D, Snyder C, Lynch JF, Lynch HT et al. Parental communication of BRCA1/2 genetic test results to children. Patient Educ Couns 2001;42:213-224.

9. Tercyak KP, Peshkin BN, DeMarco TA, Brogan BM, Lerman C. Parent-child factors and their effect on communicating BRCA1/2 test results to children. Patient Educ Couns 2002;47:145-153.

10. Bonadona V, Saltel P, Desseigne F, Mignotte H, Saurin JC, Wang Q et al. Cancer patients who experienced diagnostic genetic testing for cancer susceptibility: reactions and behavior after the disclosure of a positive test result. Cancer Epidemiol Biomarkers Prev 2002;11:97-104.

11. Lodder L, Frets PG, Trijsburg RW, Meijers-Heijboer EJ, Klijn JGM, Duivenvoorden $\mathrm{HJ}$ et al. Psychological impact of receiving a BRCA1/BRCA2 test result. Am J Med Genet 2001;98:15-24.

12. Lynch HT, Lemon SJ, Durham C, Tinley ST, Connolly C, Lynch JF et al. A descriptive study of BRCA1 testing and reactions to disclosure of test results. Cancer 1997; 79:2219-2228.

13. Easton DF, Ford D, Bishop DT, the Breast Cancer Linkage Consortium. Breast and ovarian cancer incidence in BRCA1-mutation carriers. Am J Hum Genet 1995;56: 265-271.

14. Ford D, Easton DF, Stratton M, Narod S, Goldgar D, Devilee P et al, the Breast Cancer Linkage Consortium. Genetic heterogeneity and penetrance analysis of the BRCA1 and BRCA2 genes in breast cancer families. Am J Hum Genet 1998;62:676689.

15. Struewing JP, Hartge P, Wacholder S, Baker SM, Berlin M, McAdams M et al. The risk of cancer associated with specific mutations of BRCA1 and BRCA2 among Ashkenazi Jews. N Engl J Med 1997;336:1401-1408.

16. Burke W, Daly M, Garber J, Botkin J, Kahn MJE, Lynch P et al. Recommendations for follow-up care of individuals with an inherited predisposition to cancer. JAMA 1997;277:997-1003.

17. King MC, Rowell S, Love SM. Inherited breast and ovarian cancer: What are the risks? What are the choices? JAMA 1993;269:1975-1980.

18. Hughes C, Lynch H, Durham C, Snyder C, Lemon S, Narod S et al. Communication of BRCA1/2 test results in hereditary breast cancer families. Cancer Res Ther Control 1999;8:51-59.

19. U.S. Census Bureau, 2000. Available at: http://factfinder.census.gov Accessed May 7 , 2003.

20. Lerman C, Seay J, Balshem A, Audrain J. Interest in genetic testing among firstdegree relatives of breast cancer patients. Am J Med Genet 1995;57:385-392.

21. Hilton BA. Family communication patterns in coping with early breast cancer. West J Nurs Res 1994;16:366-391.

22. American Society of Clinical Oncology (ASCO). American Society of Clinical Oncology policy statement update: genetic testing for cancer susceptibility. J Clin Oncol 2003;21:1-10.

23. Peterson SK, Watts BG, Koehly LM, Vernon SW, Baile WF, Kohlmann WK et al How families communicate about HNPCC genetic testing: findings from a qualitative study. Am J Med Genet 2003;119C:78-86.

24. Miesfeldt S, Cohn WF, Jones SM, Ropka ME, Weinstein JC. Breast cancer survivors' attitudes about communication of breast cancer risk to their children. Am J Med Genet 2003;119C:45-50.

25. Dugan RB, Wiesner GL, Juengst ET, O'Riordan MA, Matthews AL, Robin NH. Duty to warn at-risk relatives for genetic disease: genetic counselors' clinical experience. Am J Med Genet 2003;119C:27-34.

26. Lehmann LS, Weeks JC, Klar N, Biener L, Garber JE. Disclosure of familial genetic information: perceptions of the duty to inform. Am J Med 2000;109:705-711. 